\title{
Hepatic Artery Embolization Induces the Local Overexpression of Transforming Growth Factor $\beta 1$ in a Rat Hepatoma Model
}

\author{
Eisuke Ueshima $^{\text {a }}$ Hideyuki Nishiofuku $^{\text {b Haruyuki Takakic Yutaka Hiratad }}{ }^{d}$ \\ Hiroshi Kodamac ${ }^{c}$ Toshihiro Tanaka $^{b}$ Kimihiko Kichikawa ${ }^{b}$ Koichiro Yamakado ${ }^{c}$ \\ Takuya Okada $^{a}$ Keitaro Sofue ${ }^{a}$ Masato Yamaguchi ${ }^{a}$ Koji Sugimoto ${ }^{a}$ \\ Takamichi Murakami ${ }^{a}$

\begin{abstract}
a Department of Diagnostic and Interventional Radiology, Kobe University, Kobe, Japan; ${ }^{b}$ Department of Radiology, Nara Medical University, Kashihara, Japan; ' $D$ Department of Radiology, Hyogo College of Medicine, Nishinomiya, Japan; d Department of Physiology, Hyogo College of Medicine, Nishinomiya, Japan
\end{abstract}

\author{
Keywords \\ Hepatic arterial embolization · Hepatoma - Hypoxia-inducible factor $1 \alpha \cdot$ Hypoxia \\ Transforming growth factor $\beta 1$
}

\begin{abstract}
Introduction: The underlying mechanism involved in the recurrence of hepatoma after hepatic arterial embolization (HAE) is not adequately examined. An immunosuppressive cytokine, transforming growth factor $\beta 1$ (TGF- $\beta 1$ ), can lead to tumor progression and is affected by hypoxia in various cancers. The study aimed to assess the effect of HAE on the expression of TGF- $\beta 1$ in a rat hepatoma model. Methods: Sprague-Dawley rats bearing N1S1 hepatoma cells underwent HAE (HAE group, $n=5$ ) or sham treatment (sham group, $n=4$ ). The animals were euthanized at $48 \mathrm{~h}$, and liver tissues were harvested. Immunohistochemistry (IHC) and quantitative polymerase chain reaction (qPCR) were performed to compare the expression of TGF- $\beta 1$ and hypoxia-inducible factor $1 \alpha(\mathrm{HIF}-1 \alpha)$ between the HAE and sham groups. In vitro experiments with the N1S1 cell line were also performed under normoxic $\left(21 \% \mathrm{O}_{2}\right)$ or hypoxic $\left(1 \% \mathrm{O}_{2}\right)$ conditions for $48 \mathrm{~h}$, and the expression of TGF- $\beta 1$ and HIF-1 $\alpha$ was assessed with western blotting and enzyme-linked immunosorbent assay. Statistical data comparisons were performed by Student $t$ test. Results: IHC showed that both the TGF- $\beta 1$-positive and HIF-1 $\alpha$ positive tumor peripheral areas were larger in the HAE group (6.59 \pm 2.49 and $10.26 \pm 4.14 \%$; $p<0.001$, respectively) than in the sham group ( $0.34 \pm 0.41$ and $0.40 \pm 0.84 \%$ respectively). Similarly, qPCR showed that the mRNA expression levels of TGF- $\beta 1$ and HIF- $1 \alpha$ were higher (1.95 \pm 0.38 -fold and $1.62 \pm 0.37$-fold; $p<0.001$ and $p=0.002$, respectively) in the HAE group
\end{abstract}


than those in the sham group. TGF- $\beta 1$ expression was suppressed when HIF- $1 \alpha$ inhibitors were added ( $p=0.001)$, and HIF-1 $\alpha$ expression was upregulated when exogenous TGF- $\beta 1$ was added $(p=0.033)$ in N1S1 cells. Conclusion: HAE enhanced local TGF- $\beta 1$ expression in a rat hepatoma model. In vitro experiments suggest that HAE-induced hypoxic stress may trigger the interdependent expression of TGF- $\beta 1$ and HIF- $1 \alpha$.

(c) 2019 The Author(s)

Published by S. Karger AG, Basel

\section{Introduction}

Hepatoma is the second leading cause of cancer-related death globally [1]. Hepatic arterial embolization (HAE) plays a central role in the management of intermediate stage hepatoma [2,3]. As hepatomas are predominantly supplied by the hepatic artery, the blockage of their arterial supply by HAE can induce tumor hypoxia and necrosis. However, even if a complete response is achieved, $>40 \%$ of patients develop recurrence at 1 year after HAE, and the prognosis of these patients is unfavorable [4]. Therefore, identifying the underlying mechanism involved in recurrence after HAE is important to establish a more effective therapeutic strategy and improve patient survival.

Recently, several studies reported that the overexpression of transforming growth factor $\beta 1$ (TGF- $\beta 1$ ) is an independent risk factor of poor prognosis in patients with hepatoma [5-7]. TGF- $\beta 1$ is a cytokine that is strongly associated with cell growth and proliferation [8]. Moreover, TGF- $\beta 1$ also functions as an immunosuppressive cytokine in the cancer microenvironment and drives immune evasion, leading to resistance to anti-cancer treatment [9-11]. The expression of TGF- $\beta 1$ is affected by various stimulations. Recent studies have shown that hypoxic stress may induce the overexpression of TGF- $\beta 1$ [12]. Based on previous findings, we hypothesized that hypoxic stress induced by HAE may trigger the overexpression of TGF- $\beta 1$ in the tumor microenvironment. The study aimed to assess the effect of HAE on the expression of TGF- $\beta 1$ in a rat hepatoma model.

\section{Materials and Methods}

Tumor Cell Line

The N1S1 rat hepatoma cell lines were obtained from the manufacture (ATCC, Manassas, VA, USA) and used to in vivo and in vitro in this study. These N1S1 cells were cultured in Iscove's Modified Dulbecco's Medium (IMDM) supplemented with $10 \%$ fetal bovine serum (FBS) at $37^{\circ} \mathrm{C}, 5 \% \mathrm{CO}_{2}$ in a humidified incubator.

\section{Rat Hepatoma Model}

Sprague-Dawley rats (SLC, Hamamatsu, Japan) were used in this study. Animals were housed in cages with food and water available ad libitum. The room was maintained with 12-h light/dark cycle and kept at $25^{\circ} \mathrm{C}$. All animal experiments were approved by the Institutional Animal Care and Use Committee, and were conducted according to the Fundamental Guidelines for Proper Conduct of Animal Experiments and Related Activities in Academic Research Institutions in Japan. Surgical procedures in this study were performed under the anesthesia with an intraperitoneal injection of $0.3 \mathrm{mg} / \mathrm{kg}$ of medetomidine (Domitol; Nippon Zenyaku Kogyo Co., Ltd., Fukushima, Japan), 4.0 mg/kg of midazolam (Dormicum injection; Astellas Pharma Inc., Tokyo, Japan), and $5.0 \mathrm{mg} / \mathrm{kg}$ of butorphanol (Butorphanol Tartrate; FUJIFILM Wako Pure Chemical Corporation, Osaka, Japan).

Rat orthotopic hepatoma model was established under the minilaparotomy. After anesthesia, the Sprague-Dawley rats were placed in a supine position. The abdominal skin incision was made and the left lobe of the liver was exposed. Then, a total of 2.0-2.5 $\times 10^{6} \mathrm{~N} 1 \mathrm{~S} 1$ cells in $50 \mu \mathrm{L}$ of phosphate-buffered saline were injected under the liver capsule by using a 26-gauge needle. After tumor cell injection, the injection site 


\section{Liver Cancer}

\begin{tabular}{|c|c|}
\hline \multicolumn{2}{|l|}{ Liver Cancer 2020;9:63-72 } \\
\hline DOI: $10.1159 / 000502774$ & $\begin{array}{l}\text { (c) } 2019 \text { The Author(s). Published by S. Karger AG, Basel } \\
\text { www.karger.com/lic }\end{array}$ \\
\hline
\end{tabular}

Ueshima et al.: Hepatic Arterial Embolization Induces the Local TGF- $\beta 1$ Expression

was manually compressed for 5-10 min to avoid the reflux of injected cells. Then, the skin was closed by sutures and the rats were allowed to recover. The growth of the implanted tumors was monitored by ultrasonography.

\section{Hepatic Artery Embolization}

When the implanted liver tumor became $>1 \mathrm{~cm}$, rats were assigned to receive HAE (group, $n=5$ ) or sham treatment (sham group, $n=4$ ). After anesthesia, the left neck was dissected through a 2 -cm-long skin incision and the left common carotid artery was isolated carefully from the vagus nerve. Then, the left common carotid artery was cannulated by a 20-gauge intravenous catheter (Angiocath; BD Biosciences, San Jose, CA, USA), and a 1.6-Fr custom made 40-cm long microcatheter (Carnelian Marvel; Tokai Medical Products, Aichi, Japan) with a 0.014-inch guidewire (Transcend; Boston Scientific, Marlborough, MA, USA) was inserted through the intravenous catheter. The microcatheter was advanced in to the proper hepatic artery under the fluoroscopic guidance. Then, HAE was performed with $75 \mu \mathrm{m}$ microsphere (Embozene TANDEM; Merit Medical Systems, South Jordan, UT, USA) diluted by contrast agent (Iopamiron 370, Bayer Yakuhin, Osaka, Japan). Embolizaion was ceased when the blood flow of proper hepatic artery became to-and-fro. Sham procedure was performed in the same way of inserting catheter without embolization. After embolization, the intravenous catheter was removed, the left common carotid artery was ligated, and the neck incision was closed by an uninterrupted suture.

Animals were euthanized at 2 days after HAE or sham treatment. Implanted tumors with surrounding liver tissues were harvested for the histopathological and the quantitative polymerase chain reaction (qPCR) analyses. For the enzyme-linked immunosorbent assay (ELISA), blood samples were collected from inferior vena cava and the blood serums were cryopreserved until the time of assay.

\section{Histopathological Analysis}

The harvested liver tissues were fixed in $4 \%$ paraformaldehyde for TGF- $\beta 1$ staining and in Bouin solution for hypoxia-inducible factor $1 \alpha$ (HIF-1 $\alpha$ ) staining. After dehydration by ethanol, tissues were embedded in paraffin, sectioned at $5 \mu \mathrm{m}$ thickness, and mounted on the microscope slides. One section was stained with hematoxylin and eosin and the contiguous sections were immunofluorescently stained as following; the sections were heated at $120^{\circ} \mathrm{C}$ for $10 \mathrm{~min}$ to facilitate antigen retrieval. After deparaffinization and rehydration, slides were incubated with $1 \%$ hydrogen peroxide solution. After washing and blocking by skim milk, the slides were incubated with the primary antibodies overnight at $4{ }^{\circ} \mathrm{C}$. The rabbit polyclonal antibodies to TGF- $\beta 1$ (250576; ABBIOTEC, San Diego, CA, USA) diluted at 1:200 and HIF-1 $\alpha$ (GTX127309; GeneTex, Irvine, CA, USA) diluted at 1:100 were used as primary antibodies. After rinses in buffer, the slides were incubated with the biotinylated secondary antibody (Ultra-Sensitive ABC Peroxidase Rabbit IgG Staining Kit; Thermo Fisher Scientific K.K., Tokyo, Japan). Tissue staining was visualized with a DAB substrate chromogen solution (Thermo Fisher Scientific K.K., Tokyo, Japan). Then, slides were counterstained with hematoxylin, dehydrated, and sealed under a coverslip. Mouse liver samples that are known to express HIF- $1 \alpha$ were used as a positive control.

The immunohistochemistry-stained slides were scanned with a microscope (BX53M; Olympus, Tokyo, Japan) at high resolution, and accumulative 10 regions ( 5 regions from peripheral and intratumoral areas respectively) on each slide were acquired at high magnification ( $\times 40$ ). The TGF- $\beta 1$ and HIF- $1 \alpha$ positive area were detected by Image J software (National Institutes of Health, Bethesda, MD, USA, http://rsb.info.nih.gov/ $\mathrm{ij} /$ )). The software was used to perform the quantification using the built-in "Color Deconvolution" tool to extract brown color channels [13]. Quantifications of TGF- $\beta 1$ and HIF- $1 \alpha$ expressions were performed by calculating the positive proportion (\%) divided tissue staining positive area by the total area in each sample.

\section{mRNA Extraction and Quantitative Real-Time PCR}

The tumors of the harvested liver tissues were stored in the RNA stabilization solution (RNA save; Biological Industries, Cromwell, CT, USA). qPCR was performed to determine the changes in mRNA expressions of TGF- $\beta 1$ and HIF- $1 \alpha$ in the rat livers after embolization. In addition, the mRNA expressions of $\alpha$-smooth muscle actin $(\alpha-$ SMA $)$ and collagen type- $1 \alpha-1$ chain were also evaluated because $\alpha$-SMA positive cells are activated by TGF- $\beta 1$ and promote the collagen deposition [14]. Extraction of total RNA was carried out by using a NucleoSpin RNA kit including DNase (TAKARA BIO, Shiga, Japan) in accordance with the manufacturer's instructions. cDNA was synthesized using the PrimeScript First Strand cDNA Synthesis Kit (TAKARA BIO, Shiga, Japan). Quantitative real-time PCR was performed using $2.0 \mathrm{ng} / \mu \mathrm{L} c \mathrm{cDNA}$, SYBR Premix Ex Taq II (Takara Bio, Japan) and $0.4 \mu \mathrm{M}$ primers with the QuantStudio ${ }^{\mathrm{TM}} 12 \mathrm{~K}$ Flex Real-Time PCR System (Thermo 
Fisher Scientific). The reactions were incubated at $95^{\circ} \mathrm{C}$ for $30 \mathrm{~s}$ followed by 40 cycles of $95^{\circ} \mathrm{C}$ for $5 \mathrm{~s}$ and $60{ }^{\circ} \mathrm{C}$ for $30 \mathrm{~s}$, with a final dissociation curve at $95^{\circ} \mathrm{C}$ for $15 \mathrm{~s}, 60^{\circ} \mathrm{C}$ for $60 \mathrm{~s}$ and $95^{\circ} \mathrm{C}$ for $15 \mathrm{~s}$. Dissociation curve analysis of amplified products was performed at the end of each PCR reaction to confirm that only one PCR product was amplified and detected.

The specific forward and reverse primer pairs for TGF- $\beta 1$ ( $5^{\prime}$-caacaattcctggcgttacct- $3^{\prime}$ and $5^{\prime}$-aaagccctgtattccgtctcc-3'), HIF-1 $\alpha \quad\left(5^{\prime}\right.$-ctcccatacaaggcagcagaaa- $3^{\prime}$ and $5^{\prime}$-caaaacaaccaacagaaacgaaac- $\left.3^{\prime}\right), \alpha$-SMA $\left(5^{\prime}\right.$-ggatcagcgccttcagttct- $3^{\prime}$ and $5^{\prime}$-gggctagaagggtagcacat- $\left.3^{\prime}\right)$, collagen type- $1 \alpha-1$ chain $\left(5^{\prime}\right.$-cagtcgattcacctacagcacg- $3^{\prime}$ and $5^{\prime}$-gggatggagggagtttacacg- $\left.3^{\prime}\right)$, and $\beta$-actin $\left(5^{\prime}\right.$-cactttctacaatgagctgcg- $3^{\prime}$ and $5^{\prime}$ - ctggatggctacgtacatgg- $3^{\prime}$ ) were designed for rat sample respectively. Gene expression was normalized by $\beta$-actin as an internal control.

\section{Cell Culture}

$1 \times 10^{6} \mathrm{~N} 1 \mathrm{~S} 1$ cells were incubated at $10 \mathrm{~cm}$ dish with $5 \mathrm{~mL}$ IMDM medium including $10 \%$ FBS. After overnight incubation in the normoxic condition $\left(21 \% \mathrm{O}_{2}\right)$, IMDM medium including $10 \%$ FBS was replaced. Then, cells were incubated under the normoxic or hypoxic $\left(1 \% \mathrm{O}_{2}\right)$ condition for up to $48 \mathrm{~h}$.

As a positive control, the $\mathrm{N} 1 \mathrm{~S} 1$ cells added with $\mathrm{CoCl}_{2}$ (Nacalai Tesque, Kyoto, Japan), a chemical inducer of HIF-1 $\alpha$, with concentration of $100 \mu \mathrm{mol} / \mathrm{L}$ were used [15]. In order to evaluate the effect of HIF-1 $\alpha$ on TGF- $\beta 1$ expression, LW6 (20 $\mu \mathrm{mol} / \mathrm{L}$; Merck Millipore, Massachusetts, MA, USA) and FM19G11 (300 nmol/L; Sigma-Aldrich, St. Louis, MO, USA), HIF- $1 \alpha$ inhibitors that block different parts of HIF-1 $\alpha$ pathway, were used $[16,17]$. Similarly, in order to evaluate the effect of TGF- $\beta 1$ on HIF- $1 \alpha$ expression, recombinant TGF- $\beta 1$ (Peprotech, Texas, TX, USA) with concentration of $5 \mathrm{mg} / \mathrm{mL}$ in IMDM medium without FBS was used [18].

\section{Western Blotting}

Immunoblot analysis was performed to quantify the protein levels of TGF- $\beta 1$ and HIF- $1 \alpha$ in rat hepatoma cells (N1S1). Cell lysates were prepared using a radioimmunoprecipitation assay buffer (RIPA Buffer [10×]; Nacalai Tesque, Kyoto, Japan) supplemented with a phosphatase inhibitor. Protein concentration was quantified by using a protein quantification kit (Dojindo, Kumamoto, Japan), and samples were processed by using general protocol for western blotting. Membranes were incubated overnight at $4{ }^{\circ} \mathrm{C}$ with the following antibodies in Can Get Signal Solution 1 (TOYOBO, Osaka, Japan): anti-TGF- $\beta 1$ (1:1,000, ABB250576; ABBIOTEC), HIF-1 $\alpha$ (1:1,000; GTX127309; GeneTex) and anti- $\beta$-actin antibody (1:1,000; Sigma-Aldrich). After washing, membranes were incubated with the appropriate secondary antibody conjugated to horseradish peroxidase, and exposed to the ECL Plus Western blotting detection system (GE Healthcare Bio-Sciences, Piscataway, NJ, USA). The signals were detected by using a Chemilumino analyzer LAS-4000 (Fujifilm, Tokyo, Japan). The relative densities of gel bands were semiquantified by using Image J software. The adjusted relative density of TGF- $\beta 1$ and HIF- $1 \alpha$ protein was then obtained after dividing its values with the relative density of $\beta$-actin expression as a normalized loading control.

\section{Enzyme-Linked Immunosorbent Assay}

ELISA was used to quantify the TGF- $\beta 1$ secretion of N1S1 cells. The concentration of TGF- $\beta 1$ in the supernatant of N1S1 cell culture was measured using the TGF- $\beta 1$ ELISA kit (Quantikine ELISA kit; R\&D Systems, Minneapolis, MN, USA) according to the manufacturer's protocol. The optical density measurements were performed at $490 \mathrm{~nm}$ in a microplate reader (SPECTRA max; Molecular Devices, San Jose, CA, USA).

\section{Statistical Analysis}

All in vitro experiments were repeated in at least triplicate. Data were aggregated and expressed as means \pm SD unless otherwise indicated. Statistical analyses were performed using PRISM 8 software (2018, GraphPad; San Diego, CA, USA). Statistical data comparisons were performed by Student $t$ test. All test results were considered significant at $p$ values lower than 0.05 .

\section{Results}

HAE Enhanced both TGF- $\beta 1$ and HIF-1a Expression in the Peripheral Area of the Tumor Hematoxylin and eosin staining showed that necrotic areas were mainly located in the center of the tumor in the HAE group, while viable hepatoma cells were sparse in the peripheral 


\section{Liver Cancer}

\begin{tabular}{l|l}
\hline Liver Cancer 2020;9:63-72 \\
\hline DOI: 10.1159/000502774 & $\begin{array}{l}\text { @ 2019 The Author(s). Published by S. Karger AG, Basel } \\
\text { www.karger.com/lic }\end{array}$ \\
\hline
\end{tabular}

Ueshima et al.: Hepatic Arterial Embolization Induces the Local TGF- $\beta 1$ Expression
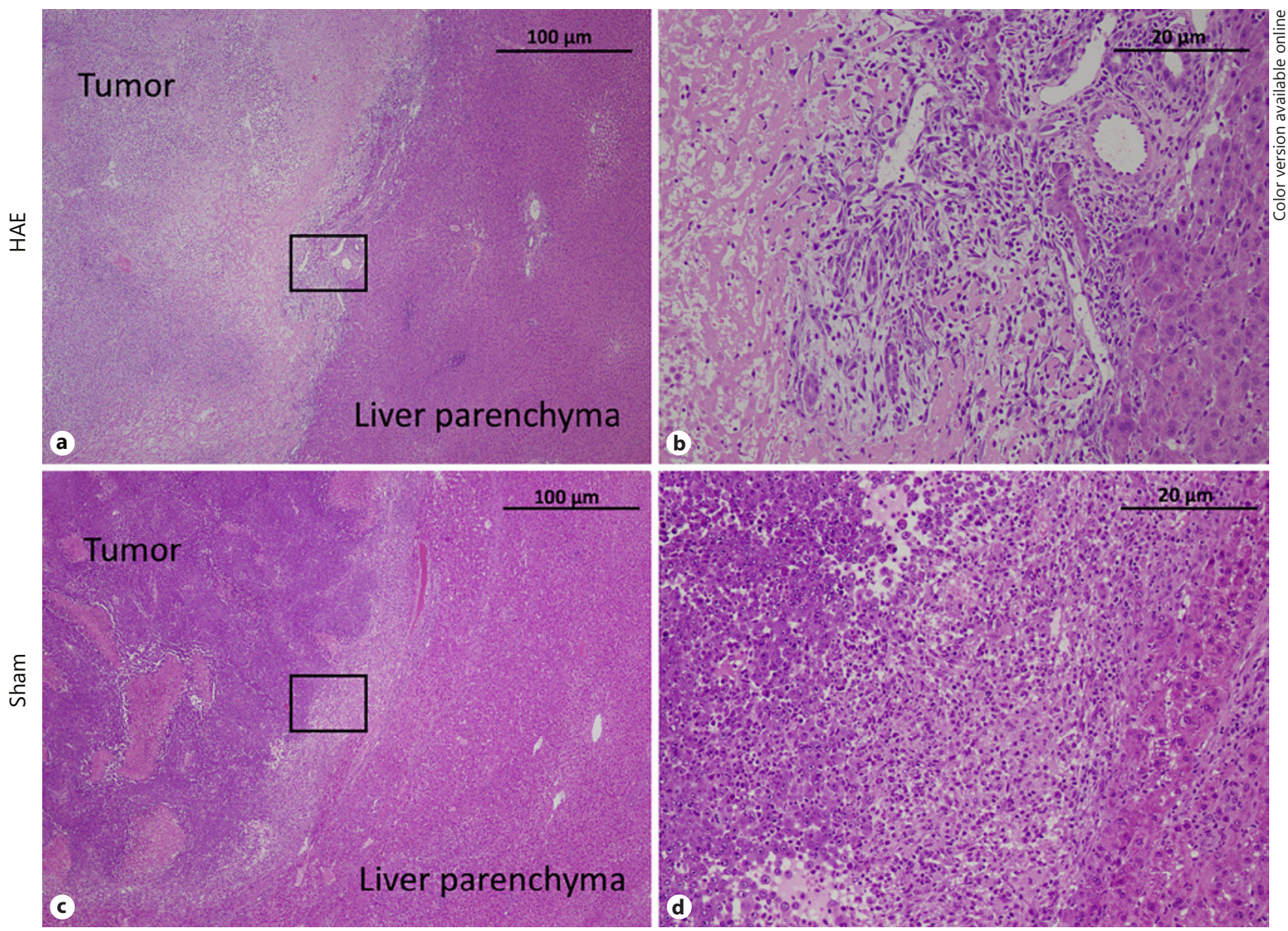

Fig. 1. Histological images of liver sections on day 2 after HAE and sham treatments. a The hematoxylin and eosin-stained liver sections revealed that necrosis was widespread in the tumoral area (tumor) and reduced in the liver parenchyma in the HAE group. $\mathbf{c}$ In the sham group, necrotic lesions were sparse in the tumoral area (tumor) and not observed in the liver parenchyma. $\mathbf{b}, \mathbf{d}$ Magnified images $(\times 200)$ of the area in the black frame in a and c, respectively. HAE, hepatic arterial embolization.

area (Fig. 1a, b). However, the necrotic area in the sham group was limited to the tumor, and the infiltration of inflammatory cells such as neutrophils was observed at the boundary of the tumor and liver parenchyma (Fig. 1c, d).

Immunohistochemistry showed that the TGF- $\beta 1$-positive area in the peripheral area of the tumor was significantly larger in the HAE group than in the sham group (6.59 \pm 2.49 and $0.34 \pm 0.41 \%$, respectively; $p<0.001$; Fig. $2 \mathrm{a}-\mathrm{e}$ ). Similarly, the HIF- $1 \alpha$-positive area in the peripheral area of the tumor was significantly larger in the HAE group than in the sham group $(10.26 \pm 4.14$ and $0.40 \pm 0.84 \% ; p<0.001$; Fig. 3a-e). On the other hand, TGF- $\beta 1(p=0.990)$ and HIF- $\alpha 1$ ( $p=0.134)$ expression was not significantly different between the HAE and sham groups at the center of the tumor.

As shown in Figure 4a, the mRNA levels of $\alpha$-SMA and COL1A (fibrotic markers) were higher $(6.95 \pm 2.00$-fold and $5.25 \pm 1.19$-fold respectively; $p<0.001)$ in the HAE group than in the sham group. Furthermore, in the HAE group, the TGF- $\beta 1$ mRNA level was significantly increased by $1.95 \pm 0.38$-fold $(p<0.001)$, and the HIF- $\alpha 1$ mRNA level was significantly increased by $1.62 \pm 0.37$-fold $(p=0.002)$. Although HAE induced TGF- $\beta 1$ mRNA expression in the tumor tissue, which was consistent with TGF- $\beta 1$ protein expression 


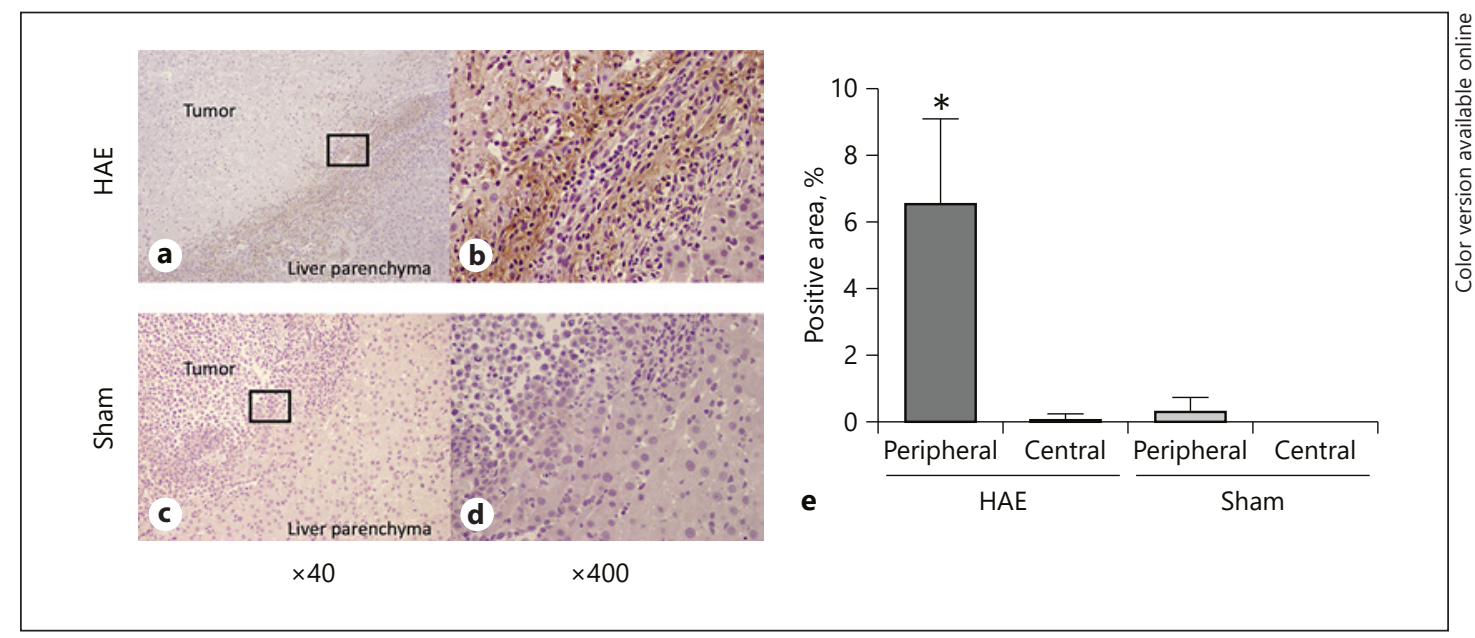

Fig. 2. TGF- $\beta 1$ expression in liver sections. a HAE group and (c) sham group. b, $\mathbf{d}$ are magnified images $(\times 400)$ of the area in the black frame in (a, c), respectively. The TGF- $\beta 1$-positive area (brown) was visible in the HAE group $(\mathbf{a}, \mathbf{b})$ but not in the sham group $(\mathbf{c}, \mathbf{d})$. e Comparison of the TGF- $\beta 1$-positive proportion (\%) in the center and periphery of the tumor in the HAE group $(n=5)$ and sham group $(n=4)$. Data are presented as the mean \pm SD. The significance level of the TGF- $\beta 1$-positive proportion (\%) in the periphery compared with the center of the tumor in the HAE group was set as $* p<0.01$ using Student $t$ test. HAE, hepatic arterial embolization.

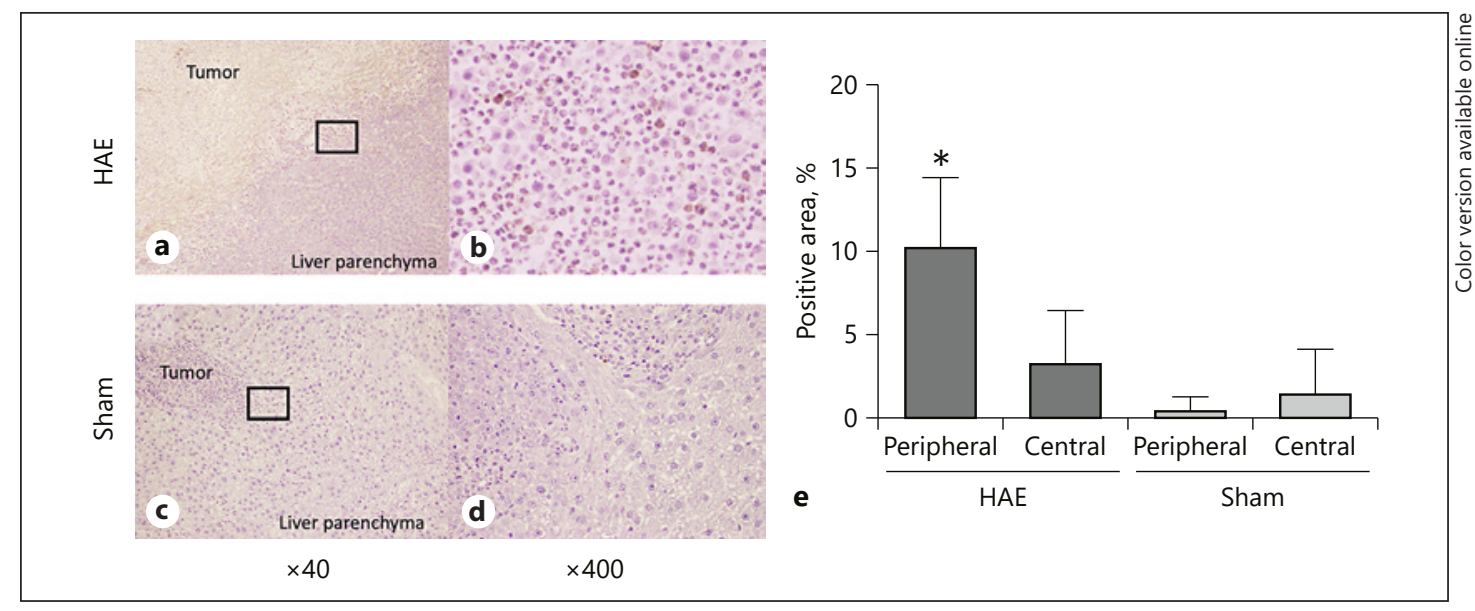

Fig. 3. HIF-1 $\alpha$ expression in liver sections. a HAE group and (c) sham group. b, $\mathbf{d}$ are magnified images $(\times 400)$ of the area in the black frame in (a, $\mathbf{c})$, respectively. The HIF-1 $\alpha$-positive area (brown) was visible in the HAE group but not in the sham group. e The histogram shows the stained positive area (\%) of each slide calculated by ImageJ software. For HAE-treated tumors, the HIF- $1 \alpha$-positive area was the largest in the peripheral area followed by the intratumoral area $(* p<0.01)$. HAE, hepatic arterial embolization.

(Fig. 3), TGF- $\beta 1$ protein secreted in the serum was not significantly different between the HAE and sham groups $(3,029 \pm 1,173$ and 3,099 $\pm 903 \mathrm{pg} / \mathrm{mL}$ respectively; $p=0.931$; Fig. 4b).

\section{Hypoxic Condition Induced TGF- $\beta 1$ and HIF-1a Expression in N1S1 Cells}

To elucidate the mechanisms of TGF- $\beta 1$ expression, an in vitro cell culture experiment under hypoxic conditions, which mimic HAE, was performed. Western blot analysis of the in 


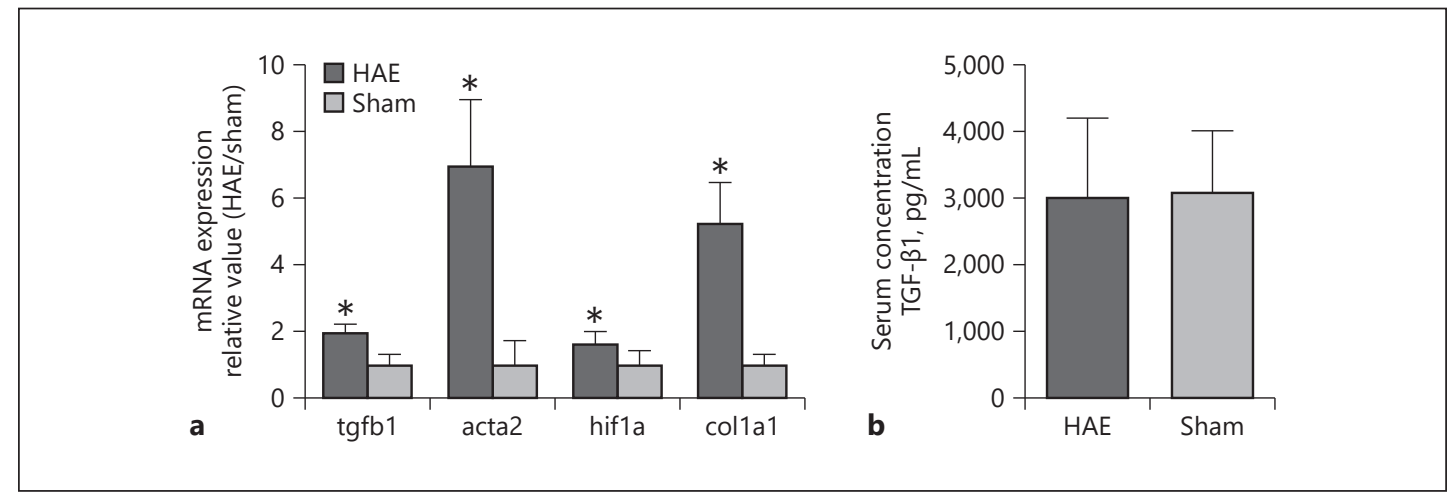

Fig. 4. Gene expression and serum concentration of TGF- $\beta 1$ in tumors. a Quantification of TGF- $\beta 1, \alpha-S M A$, HIF- $1 \alpha$, and collagen type- $1 \alpha-1$ chain mRNAs normalized to $\beta$-actin in tumors of the HAE group (black bars, $n=5$ ) and the sham group (gray bars, $n=4$ ) by qPCR. Asterisks indicate a higher ( ${ }^{*} p<0.01$ ) mRNA expression in tumors of the HAE group compared with the sham group according to Student $t$ test. b Serum TGF- $\beta 1$ protein of N1S1-bearing rats (HAE: $n=5$; sham: $n=4$ ). TGF- $\beta 1$ secretion was not significantly different between the HAE and sham groups ( $p=0.93)$ according to Student $t$ test. HAE, hepatic arterial embolization; TGF- $\beta 1$, transforming growth factor $\beta 1$.

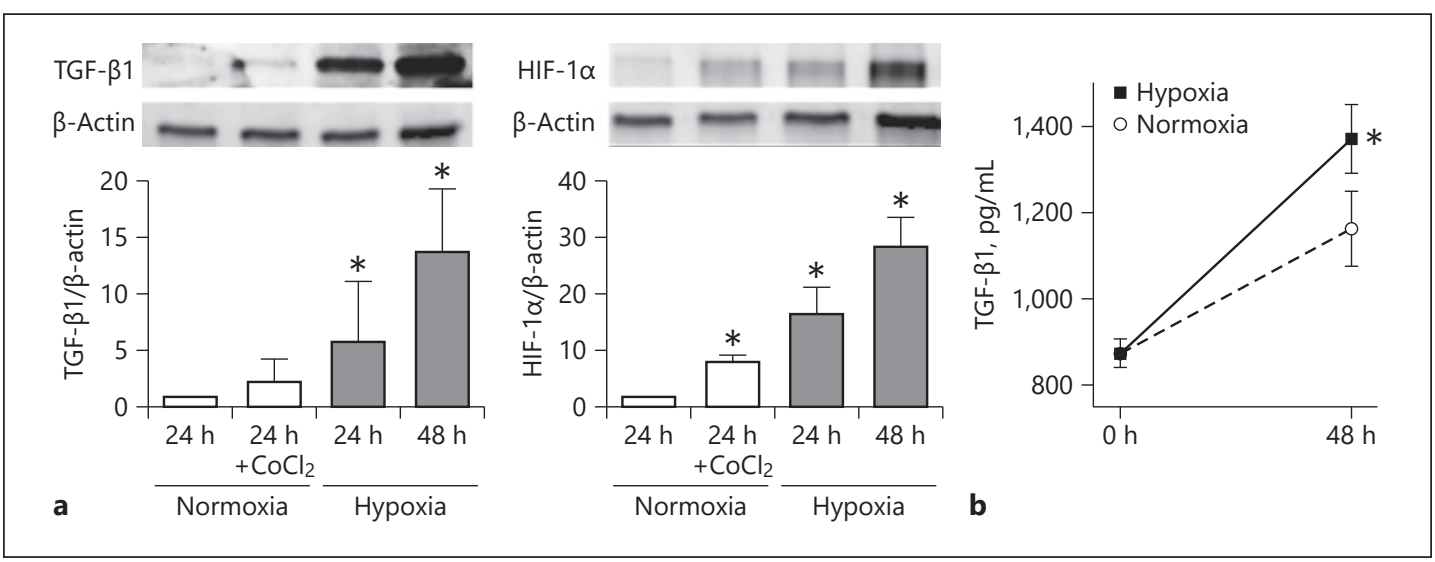

Fig. 5. Hypoxia-induced expression of TGF- $\beta 1$ and HIF- $1 \alpha$. a TGF- $\beta 1$ and HIF-1 $\alpha$ protein expression in rat hepatoma cells (N1S1) cultured under normoxic conditions $\left(21 \% \mathrm{O}_{2}\right)$ with or without $\mathrm{CoCl}_{2}(100 \mu \mathrm{mol} / \mathrm{L}$; white bar) for $24 \mathrm{~h}$ and under hypoxic conditions $\left(1 \% \mathrm{O}_{2}\right.$; black bar) for 24 and $48 \mathrm{~h}$. Representative western blots for TGF- $\beta 1$ and HIF-1 $\alpha$ protein expression (upper panel) and densitometric analysis results normalized to $\beta$-actin (lower panel) are shown. The protein expression of TGF- $\beta 1$ and HIF- $1 \alpha$ was higher $(* p<0.01)$ under hypoxic conditions than under normoxic conditions according to Student $t$ test. b TGF- $\beta 1$ secreted into the supernatant of N1S1 cells cultured under hypoxic conditions for $48 \mathrm{~h}$ was detected by ELISA. TGF- $\beta 1$ secretion was higher $(* p<0.01)$ under hypoxic conditions than under normoxic conditions according to Student $t$ test. Each experiment was performed 4 times (a, b). TGF- $\beta 1$, transforming growth factor $\beta 1$; HIF- $1 \alpha$, hypoxia-inducible factor $1 \alpha$.

vitro cell culture samples showed that the protein expression of both TGF- $\beta 1$ and HIF- $1 \alpha$ was higher ( $p=0.031$ and $p<0.001$ respectively) when the cells were incubated under hypoxic conditions instead of normoxic conditions (Fig. 5a). Similarly, ELISA of the cell culture supernatant showed that TGF- $\beta 1$ level was higher $(p<0.001)$ in samples cultured under hypoxic conditions $(1,397 \pm 58 \mathrm{pg} / \mathrm{mL})$ than in those cultured under normoxic conditions $(1,119 \pm 37$ pg/mL; Fig. 5b). 


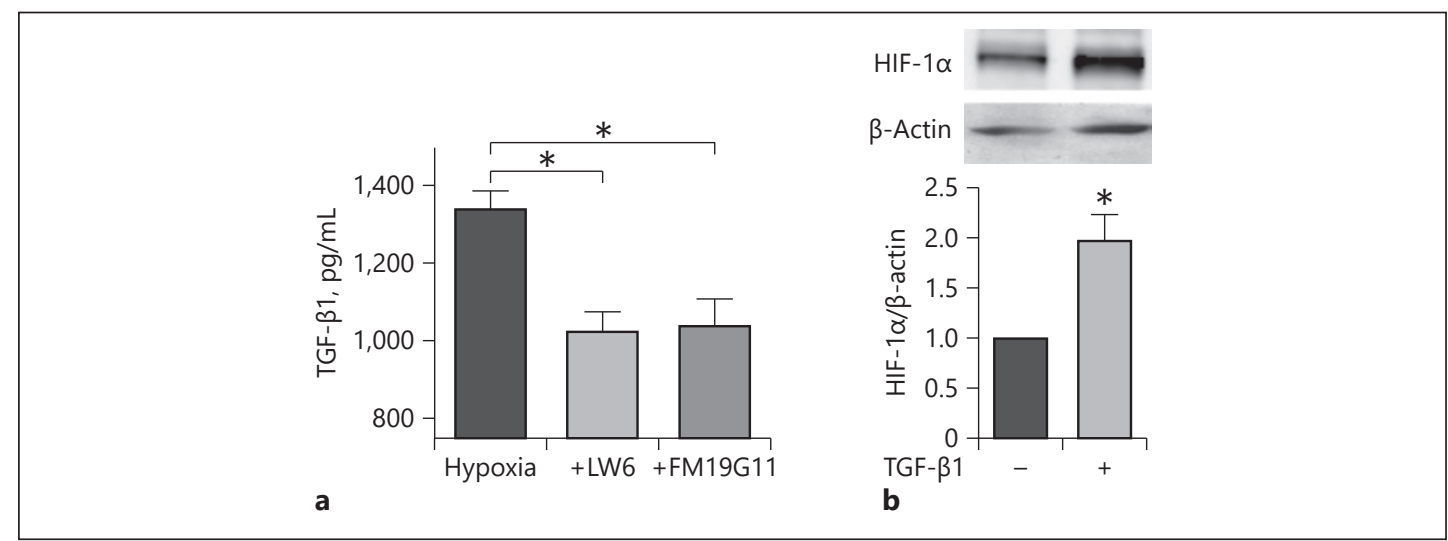

Fig. 6. Relationship between TGF- $\beta 1$ and HIF-1 $\alpha$ expression. Effect of HIF- $1 \alpha$ inhibitors on the hypoxia-induced expression of TGF- $\beta 1$. a TGF- $\beta 1$ secreted into the supernatant of N1S1 cells cultured under hypoxic conditions $\left(1 \% \mathrm{O}_{2}\right)$ for $48 \mathrm{~h}$ without or with HIF-1 $\alpha$ inhibitors $(20 \mu \mathrm{mol} / \mathrm{L} \mathrm{LW6}$ or $300 \mathrm{nmol} / \mathrm{L}$ FM19G11) was detected by ELISA. The secretion of TGF- $\beta 1$ under hypoxic conditions was significantly suppressed by HIF- $1 \alpha$ inhibitors ( $* p<0.01$ ). b A representative western blot of HIF-1 $\alpha$ expression in N1S1 cells stimulated with TGF- $\beta 1(5 \mathrm{ng} / \mathrm{mL})$ under normoxic conditions for $48 \mathrm{~h}$ (upper panel) and densitometric analysis results normalized to $\beta$-actin (lower panel). TGF- $\beta 1$ significantly induced HIF-1 $\alpha$ protein expression under normoxic conditions $(* p<0.01)$. Each experiment was performed 4 times $(\mathbf{a}, \mathbf{b})$. TGF- $\beta 1$, transforming growth factor; HIF-1 $\alpha$, hypoxia-inducible factor $1 \alpha$.

\section{Association of TGF- $\beta 1$ and HIF-1 $\alpha$ Expression in N1S1 Cells}

When LW6 and FM19G11 (HIF-1 $\alpha$ inhibitors) were added to the N1S1 cell culture medium and incubated for $48 \mathrm{~h}$ under hypoxic conditions, the TGF- $\beta 1$ level was lower in the groups with the inhibitors ( $p=0.031$ and $p<0.001$ respectively) than in the control group without the inhibitors $(1,340 \pm 46,1,026 \pm 49$, and $1,040 \pm 65 \mathrm{pg} / \mathrm{mL}$ in the control, LW6, and FM19G11 groups respectively; Fig. $6 \mathrm{a}$ ). When recombinant TGF- $\beta 1$ was added to the N1S1 cell culture medium and incubated for $48 \mathrm{~h}$ under normoxic conditions, the expression of HIF-1 $\alpha$ was significantly increased $(1.97 \pm 0.26$-fold; $p=0.033)$ compared with the expression in the control group (Fig. 6b).

\section{Discussion}

The results of our in vivo study showed that HAE could increase the local expression of TGF- $\beta 1$. The expression of TGF- $\beta 1$ has been reported to be affected by various stimulations such as inflammatory reactions [19]. Recently, Hung et al. [12] reported that hypoxic conditions induced the secretion of TGF- $\beta 1$ by mesenchymal stem cells. In our study, TGF- $\beta 1$ positive areas were predominantly located in the peripheral area of the tumor, where residual viable hepatoma cells were sparse, after HAE. Moreover, the overexpression of HIF-1 $\alpha$ was observed in the peripheral area of the tumor. HIF-1 $\alpha$ is known to function as a transcriptional regulator that upregulates several cancer-related genes [20]. Therefore, we hypothesized that hypoxic stress induced by HAE may trigger the overexpression of TGF- $\beta 1$ in residual hepatoma cells in an HIF-1 $\alpha$-dependent manner.

The results of our in vitro experiment support our hypothesis. The overexpression of TGF- $\beta 1$ was observed when rat N1S1 hepatoma cells were cultured under hypoxic conditions, and it was downregulated when an HIF-1 $\alpha$ inhibitor was used. More interestingly, the expression of HIF- $1 \alpha$ was higher when exogenous TGF- $\beta 1$ was added. These results suggest 
that the expression of TGF- $\beta 1$ and HIF- $1 \alpha$ may be interdependent. Similarly, Basu et al. [21] reported the interdependent signaling of HIF- $1 \alpha$ and TGF- $\beta /$ Smad3 in renal epithelial cells under hypoxic conditions, which could lead to renal fibrogenesis.

Notably, the mRNA expression of both $\alpha$-SMA and COL1A was also considerably upregulated after HAE in the rat hepatoma model. TGF- $\beta 1$ is known to induce the transformation of hepatic stellate cells to myofibroblasts, which express $\alpha$-SMA $[22,23]$. Moreover, these $\alpha$-SMA-positive myofibroblasts induce collagen deposition. Therefore, the high mRNA expression of both $\alpha$-SMA and COL1A may indicate the abundant secretion of TGF- $\beta 1$ in the tumor microenvironment. However, serum TGF- $\beta 1$ level was not higher in the HAE group in this study, suggesting that the overexpression of TGF- $\beta 1$ after HAE was locally limited and more obvious compared with the serum level of TGF- $\beta 1$.

TGF- $\beta 1$ can promote cancer cell growth, proliferation, and immune evasion [9-11]. The overexpression of TGF- $\beta 1$ has been reported to be associated with recurrence and poor prognosis in patients with hepatoma [5-7]. Similarly, the overexpression of HIF-1 $\alpha$ is known to be associated with poor prognosis in patients with hepatoma [24, 25]. Therefore, although HAE is a useful therapeutic option for the treatment of intermediate-stage hepatoma, the results of our study suggest that HAE may also adversely affect cancer treatment by causing the overexpression of TGF- $\beta 1$ and HIF- $1 \alpha$. Accordingly, the combined use of TGF- $\beta 1$ and HIF- $1 \alpha$ inhibitors with HAE may be a reasonable approach for enhancing the effect of HAE; however, further studies are needed.

This study has several limitations including the small number of animals, the model of hepatoma (i.e., autograft model without liver cirrhosis), and short follow-up periods. For the in vitro experiment, the samples were assessed only after $48 \mathrm{~h}$, and the kinetics of TGF- $\beta 1$ and HIF-1 $\alpha$ was not examined. Moreover, our in vitro model did not accurately represent in vivo conditions.

In conclusion, HAE enhanced the local TGF- $\beta 1$ expression in a rat hepatoma model. In vitro experiments suggest that HAE-induced hypoxic stress may trigger the interdependent expression of TGF- $\beta 1$ and HIF- $1 \alpha$.

\section{Acknowledgments}

We thank Ms. Yumi Seshi for technical assistance and the Biopathology Institute for assistance with histological preparation and immunohistochemical staining.

\section{Statement of Ethics}

All animal experiments were approved by the Institutional Animal Care and Use Committee and were conducted according to the Fundamental Guidelines for Proper Conduct of Animal Experiments and Related Activities in Academic Research Institutions in Japan.

\section{Disclosure Statement}

The authors have no conflicts of interest to declare.

\section{Funding Sources}

This study was supported by the Japan Society for the Promotion of Science: KAKENHI Grant-in-Aid for Young Scientists (B), Grant Number 17K16441. 


\section{Author Contributions}

H.N., T.T., and K.K.: animal experiments. E.U., H.T., and H.K.: histology, image analysis, and quantification. E.U., H.T., and Y.H.: in vitro experiments. E.U., H.T., Y.H., T.O., and K.S: statistical analysis and results. E.U., H.N., H.T., K.Y., M.Y., K.S., and T.M.: manuscript preparation.

\section{References}

1 Kassebaum NJ, Bertozzi-Villa A, Coggeshall MS, Shackelford KA, Steiner C, Heuton KR, et al. Global, regional, and national levels and causes of maternal mortality during 1990-2013: a systematic analysis for the Global Burden of Disease Study 2013. Lancet. 2014 Sep;384(9947):980-1004.

2 Kudo M, Matsui O, Izumi N, Iijima H, Kadoya M, Imai Y, et al.; Liver Cancer Study Group of Japan. JSH consensusbased clinical practice guidelines for the management of hepatocellular carcinoma: 2014 update by the Liver Cancer Study Group of Japan. Liver Cancer. 2014 Oct;3(3-4):458-68.

3 Arizumi T, Ueshima K, Minami T, Kono M, Chishina H, Takita M, et al. Effectiveness of sorafenib in patients with transcatheter arterial chemoembolization (TACE) refractory and intermediate-stage hepatocellular carcinoma. Liver Cancer. 2015 Dec;4(4):253-62.

4 Kinugasa H, Nouso K, Takeuchi Y, Yasunaka T, Onishi H, Nakamura S, et al. Risk factors for recurrence after transarterial chemoembolization for early-stage hepatocellular carcinoma. J Gastroenterol. 2012 Apr; 47(4):421-6.

5 Lin TH, Shao YY, Chan SY, Huang CY, Hsu CH, Cheng AL. High serum transforming growth factor- $\beta 1$ levels predict outcome in hepatocellular carcinoma patients treated with sorafenib. Clin Cancer Res. 2015 Aug; 21(16):3678-84.

6 Wang Y, Liu T, Tang W, Deng B, Chen Y, Zhu J, et al. Hepatocellular carcinoma cells induce regulatory T cells and lead to poor prognosis via production of transforming growth factor- $\beta 1$. Cell Physiol Biochem. 2016; 38(1):306-18.

7 Ji F, Fu SJ, Shen SL, Zhang LJ, Cao QH, Li SQ, et al. The prognostic value of combined TGF- $\beta 1$ and ELF in hepatocellular carcinoma. BMC Cancer. 2015 Mar;15(1):116.

8 Massagué J. TGF $\beta$ signalling in context. Nat Rev Mol Cell Biol. 2012 Oct;13(10):616-30.

9 Konkel JE, Zhang D, Zanvit P, Chia C, Zangarle-Murray T, Jin W, et al. Transforming growth factor- $\beta$ signaling in regulatory $\mathrm{T}$ cells controls $\mathrm{T}$ helper-17 cells and tissue-specific immune responses. Immunity. 2017 Apr; 46(4):660-74.

10 Wherry EJ, Kurachi M. Molecular and cellular insights into T cell exhaustion. Nat Rev Immunol. 2015 Aug; 15(8): 486-99.

11 Noy R, Pollard JW. Tumor-associated macrophages: from mechanisms to therapy. Immunity. 2014 Jul;41(1): 49-61.

12 Hung SP, Yang MH, Tseng KF, Lee OK. Hypoxia-induced secretion of TGF- $\beta 1$ in mesenchymal stem cell promotes breast cancer cell progression. Cell Transplant. 2013;22(10):1869-82.

13 Ruifrok AC, Johnston DA. Quantification of histochemical staining by color deconvolution. Anal Quant Cytol Histol. 2001 Aug;23(4):291-9.

14 Zhao XK, Yu L, Cheng ML, Che P, Lu YY, Zhang Q, et al. Focal adhesion kinase regulates hepatic stellate cell activation and liver fibrosis. Sci Rep. 2017 Jun;7(1):4032.

15 Wu D, Yotnda P. Induction and testing of hypoxia in cell culture. J Vis Exp. 2011;54:pii:2899.

16 Lee K, Kang JE, Park SK, Jin Y, Chung KS, Kim HM, et al. LW6, a novel HIF-1 inhibitor, promotes proteasomal degradation of HIF-1 $\alpha$ via upregulation of VHL in a colon cancer cell line. Biochem Pharmacol. 2010 Oct;80(7):982-9.

17 Marampon F, Gravina GL, Zani BM, Popov VM, Fratticci A, Cerasani M, et al. Hypoxia sustains glioblastoma radioresistance through ERKs/DNA-PKcs/HIF-1 $\alpha$ functional interplay. Int J Oncol. 2014 Jun;44(6):2121-31.

18 Zhou Y, Yang S, Zhang P. Effect of exogenous fetuin-A on TGF- $\beta /$ Smad signaling in hepatic stellate cells. BioMed Res Int. 2016;2016:8462615.

19 Bierie B, Moses HL. Transforming growth factor beta (TGF-beta) and inflammation in cancer. Cytokine Growth Factor Rev. 2010 Feb;21(1):49-59.

20 Semenza GL. Targeting HIF-1 for cancer therapy. Nat Rev Cancer. 2003 Oct;3(10):721-32.

21 Basu RK, Hubchak S, Hayashida T, Runyan CE, Schumacker PT, Schnaper HW. Interdependence of HIF-1 $\alpha$ and TGF- $\beta$ /Smad3 signaling in normoxic and hypoxic renal epithelial cell collagen expression. Am J Physiol Renal Physiol. 2011 Apr;300(4):F898-905.

22 Gandhi CR. Hepatic stellate cell activation and pro-fibrogenic signals. J Hepatol. 2017 Nov;67(5):1104-5.

23 Liu Z, Yi J, Ye R, Liu J, Duan Q, Xiao J, et al. miR-144 regulates transforming growth factor- $\beta 1$ iduced hepatic stellate cell activation in human fibrotic liver. Int J Clin Exp Pathol. 2015 Apr;8(4):3994-4000.

24 Huang GW, Yang LY, Lu WQ. Expression of hypoxia-inducible factor $1 \alpha$ and vascular endothelial growth factor in hepatocellular carcinoma: impact on neovascularization and survival. World J Gastroenterol. 2005 Mar; 11(11):1705-8.

25 Cao S, Yang S, Wu C, Wang Y, Jiang J, Lu Z. Protein expression of hypoxia-inducible factor-1 alpha and hepatocellular carcinoma: a systematic review with meta-analysis. Clin Res Hepatol Gastroenterol. 2014 Oct;38(5):598-603. 